\title{
Abstract
}

\section{Clinical Cancer Genetic Service in Sweden}

\section{Ulf Kristoffersson}

Department of Clinical Genetics, University
Hospital, S-221 85 Lund, Sweden

The cancer genetic service is organised as joint clinics from the six university hospitals genetics and oncology departments and each serves one of the six health care regions. The patients are usually referred from surgeons, gynaecologists or GPs, and thus selected because of an increase of cancer in the family. At the clinic a geneticist, an oncologist, and a psychosocially trained oncologic nurse usually see the patients together. The clinics co-operate in a network in part sponsored by the Swedish Cancer Fund and will, in 1999, issue national guidelines for cancer genetic service, available on Internet in Swedish, in co-operation with the Swedish Board of Health and Welfare and the Cancer Fund.

The family history of cancer is collected before the patient is seen and the information is, if necessary, checked against hospital files after proper informed consent. Risk is calculated, and if it is equivalent to that found for dominant inheritance, and if there is a relevant gene to test, and if there is a living relative with an appropriate cancer alive, mutation testing is offered to the family. The clinics do not inform other family members, but actively encourage the proband to inform other family members. 


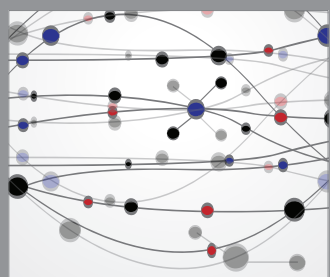

The Scientific World Journal
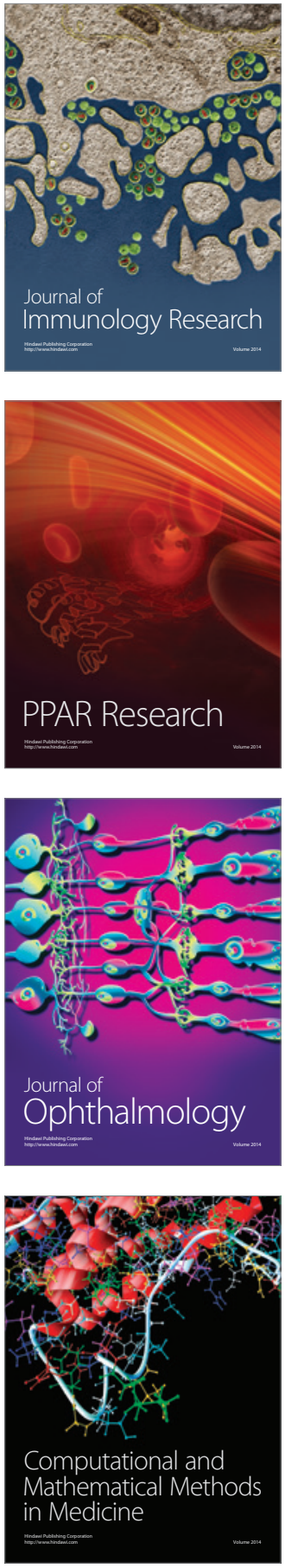

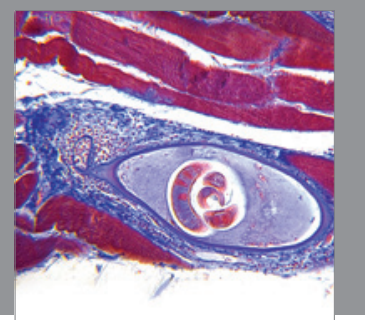

Gastroenterology

Research and Practice
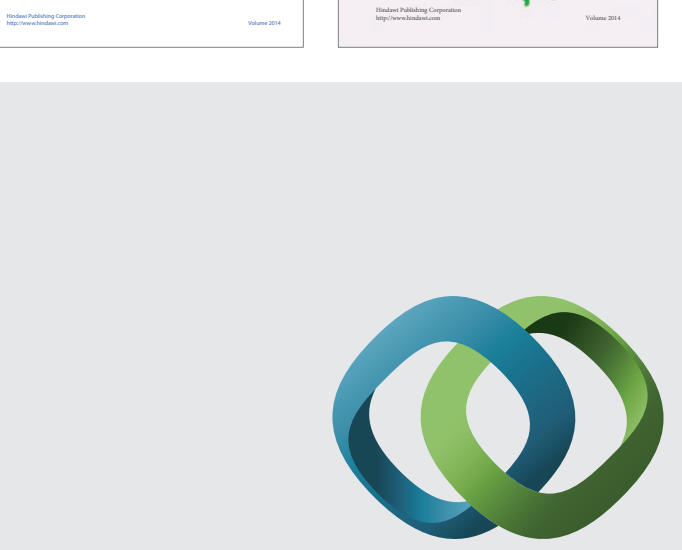

\section{Hindawi}

Submit your manuscripts at

http://www.hindawi.com
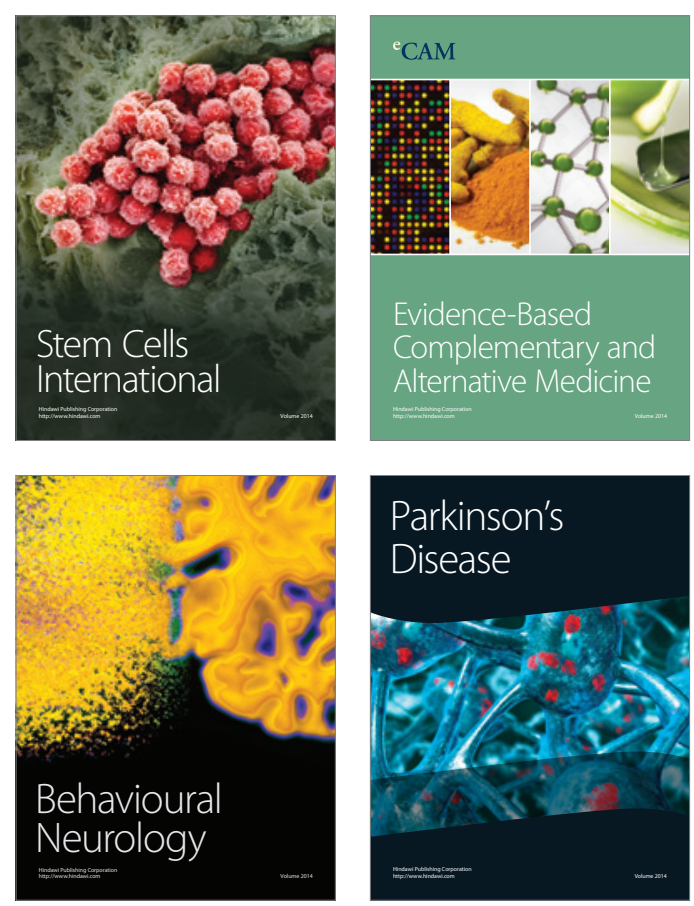

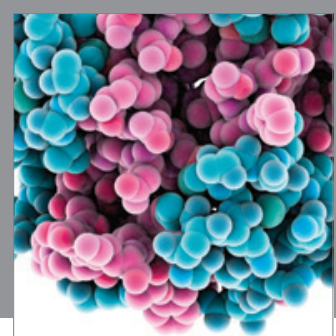

Journal of
Diabetes Research

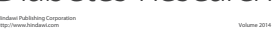

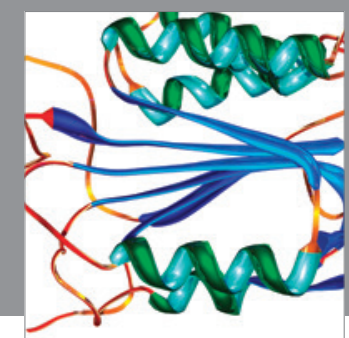

Disease Markers
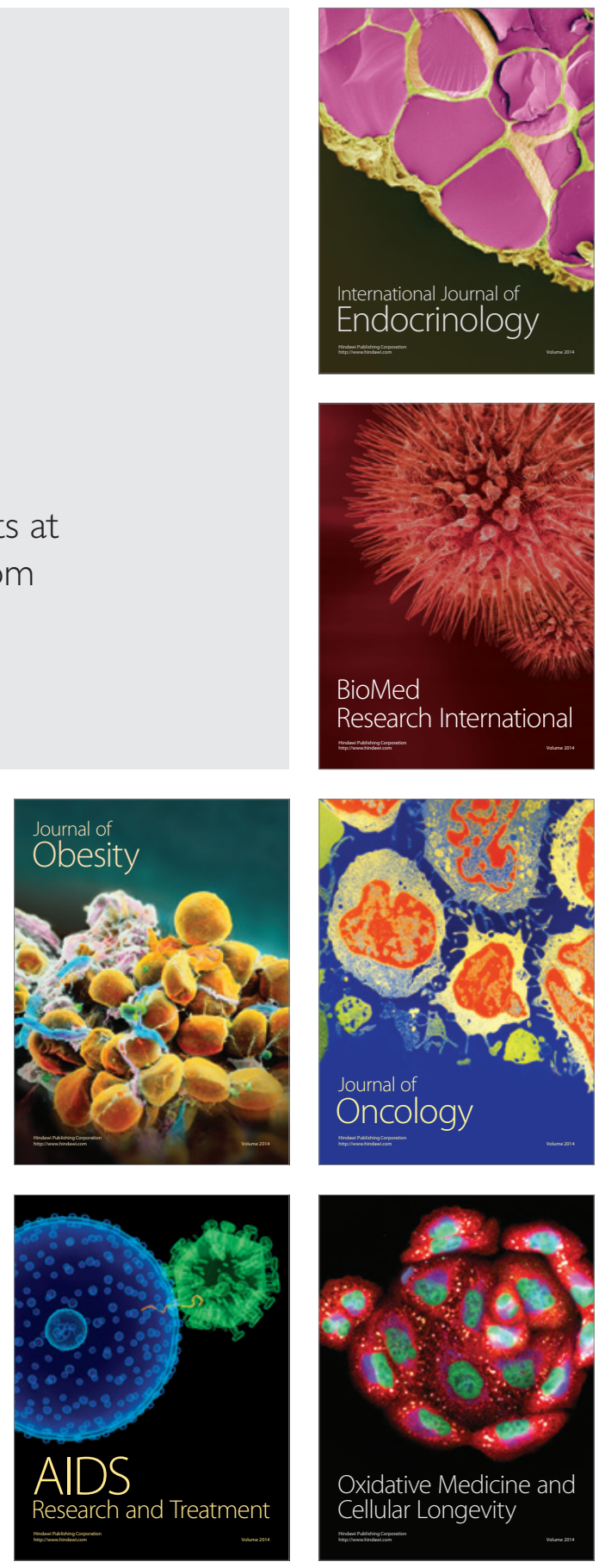